\title{
Intranasal sodium citrate solution improves olfaction in post-viral hyposmia*
}

\author{
K.L. Whitcroft" ${ }^{1 \#}$, C. Merkonidis ${ }^{1,2 \#}$, M. Cuevas ${ }^{1}$, A. Haehner ${ }^{1}$, C. Philpott ${ }^{3,4}$, \\ T. Hummel ${ }^{1}$ \\ ' Smell \& Taste Clinic, Department of ORL, TU Dresden, Dresden, Germany \\ 2 ENT Department, The Ipswich Hospital NHS Trust, Ipswich, Suffolk, United Kingdom \\ ${ }^{3}$ Norwich Medical School, University of East Anglia, Norwich, United Kingdom \\ ${ }^{4}$ The Smell \& Taste Clinic, James Paget University Hospital, Gorleston, United Kingdom
}

Rhinology 54: 368-373, 2016

DOI:10.4193/Rhino16.054

*Received for publication:

February 18, 2016

Accepted: March 31, 2016

"Both authors contributed

equally

\begin{abstract}
Background: Calcium plays an integral role in olfactory signal transduction, including feedback inhibition. Sodium citrate acts as a calcium sequestrant and when applied intranasally, reduces free calcium available for feedback inhibition, which should theoretically improve olfaction. We aimed to investigate the utility of intranasal sodium citrate in improving the olfactory function of hyposmic patients, by performing this prospective placebo controlled, single-blind trial.

Methodology: Monorhinal olfactory testing for odour identification and threshold was performed in hyposmic patients using "Sniffin'Sticks", before and after treatment. Treatment consisted of one-off sodium citrate solution application to the olfactory cleft. Sodium chloride solution was applied to the contralateral olfactory cleft, which therefore acted as placebo control. Patients were blinded to the side of sodium citrate application, and side of treatment was randomized between patients.

Results: 57 patients participated, aged 22-79. Causes of hyposmia included: post-viral (7); posttraumatic (10); sinonasal disease (30) and idiopathic (10). Compared with placebo, there was significant improvement in the identification scores of participants with post-viral hyposmia, following sodium citrate treatment. No significant change in olfactory function occurred for either identification or threshold in any other aetiological subgroup.
\end{abstract}

Conclusions: Intranasal sodium citrate may be of benefit to patients with post-viral hyposmia.

Key words: Hyposmia, anosmia, olfaction, sodium citrate, treatment

\section{Introduction}

Olfactory dysfunction is a well-documented condition, with many aetiological factors. Whilst the true prevalence is unknown, population based estimates range between 10.6 and $62.5 \%$, depending on assessment method, sample age and geographical location ${ }^{(1-5)}$. Through associated eating and weight disturbances, social anxiety and depression, olfactory dysfunction can have significant impact on quality of life ${ }^{(6,7)}$. However, little progress has been made in establishing successful longterm treatments, which may be due to the complex biochemical and neurological mechanisms involved.
The perception of odours requires both functional olfactory neuroepithelium in the nose, as well as intact higher cortical processing. Olfactory sensory neurons (ON) are found within the nasal neuroepithelium and extend their dendritic cilia into the overlying mucus layer. Here, dissolved odorants bind to olfactory receptors (OR) within the ciliary surface membrane. OR are $G$ coupled receptors and odorant binding therefore leads to $G$ protein mediated activation of adenylyl cyclase with consequent increased cyclic adenosine monophosphate (cAMP) production. In turn, increased intracellular CAMP opens cyclic nucleotide gated channels (CNG), leading to cation influx, and ultimately action potential generation ${ }^{(8)}$. 
Over recent years, it has become evident that calcium plays an integral role in OR downstream signalling cascades, including inhibitory feedback ${ }^{(9,10)}$. This inhibitory role is currently thought to involve two separate mechanisms. First, calcium-calmodulin directly interacts with the CNG leading to decreased channel sensitivity to cyclic nucleotides and thereby reduced positive current influx ${ }^{(11-13)}$. The second mechanism is thought to involve calcium dependent phosphorylation and consequent inhibition of adenylyl cyclase, with resultant decreased intracellular CAMP leading to decreased CNG activation ${ }^{(14-16)}$. The latter of these two mechanisms may be important in adaptation of the olfactory response to prolonged stimulus exposure ${ }^{(17)}$.

It has been theorized that reducing mucus free calcium levels may somehow modulate these inhibitory effects and thereby enhance olfaction. Sodium citrate acts as a calcium sequestrant, and previous work using intranasal sodium citrate in hyposmic patients has demonstrated improved olfactory function ${ }^{(18)}$. However, the existing literature on this topic is limited. Therefore, in order to further investigate the utility of intranasal sodium citrate in the treatment of olfactory dysfunction, we undertook the following prospective placebo controlled, single-blind trial.

\section{Materials and methods}

Patients for this prospective trial were recruited from the Smell and Taste Clinic, Department of Otorhinolaryngology, Technische Universität, Dresden. Patients aged 18 or older with olfactory loss were included. Those with congenital anosmia or neurodegenerative diseases were excluded. Written consent was obtained from patients prior to participation.

Patients were treated with a single application of $1 \mathrm{ml}$ intranasal sodium citrate solution (3.5g/140ml, pH 7.4, osmolarity 298) to either the right or left nasal cavity. The contralateral nasal cavity was treated with a single application of $1 \mathrm{ml}$ physiological sodium chloride solution only and therefore acted as a placebo control. The side of sodium citrate treatment was randomized between patients. During application, the patient was supine in a head back position and either sodium citrate or sodium chloride solution was applied to the olfactory cleft by an otorhinolaryngologist (CM) under endoscopic control. Patients were monitored for side effects throughout. Patients were not informed regarding side of sodium citrate administration and in this way were blinded to the results.

Monorhinal olfactory testing was undertaken using the "Sniffin' Sticks" test battery (Burghart Messtechnik, Wedel, Germany) before treatment and 20 to 30 minutes post treatment. Sniffin' Sticks are a validated psychophysical test of olfaction, and have been described extensively in the literature ${ }^{(19,20)}$. For our purpose, olfactory function was assessed at the level of odour thresholds for phenylethylalcohol (PEA), a relatively selective stimulant of the human olfactory system, and at a suprathreshold level for odour identification. Discrimination, another suprathreshold test of olfactory function, was not performed.

Threshold testing involved a 16-step staircase forced choice paradigm in which patients are scored based on their ability to distinguish a pen containing PEA from two blanks. Higher obtained scores correspond with lower olfactory threshold and better peripheral function. Patients were blindfolded and the order of pen presentation randomized. Odour identification involves a 16-step forced choice paradigm in which a patient is asked to identify an odour from a set of 4 visual and written cues. Again, a higher score indicates better olfactory function.

\section{Statistical analyses}

Statistical analysis was performed using GraphPad Prism (version 6, GraphPad Software, LaJolla California USA). Statistical significance was assumed where $p<0.05$. Unless specified otherwise, results are given as mean \pm standard deviation. Results are given to two decimal places.

\section{Ethical considerations}

This study was approved by the Ethics Committee of Technische Universität Dresden (protocol number EK 118042013). It was conducted in accordance with the Declaration of Helsinki.

\section{Results}

Fifty-seven patients were included in the trial, with ages ranging from 22 to 79. There were 7 patients with post-viral hyposmia, 10 with posttraumatic hyposmia, 30 with hyposmia due to sinonasal disease (including chronic rhinosinusitis but without gross nasal polyposis) and 10 with idiopathic hyposmia. Patient demographics, past medical history, medication history and previous treatment for hyposmia can be found in Table 1 .

Mean monorhinal olfactory scores before and after treatment with sodium citrate $(\mathrm{SC})$ or sodium chloride solution $(\mathrm{NaCl})$ for all patients and according to aetiology are shown in Table 2. Change in olfactory score after treatment $[\Delta \mathrm{NaCl} / \mathrm{SC}$, where $\Delta \mathrm{NaCl}=$ (post treatment $\mathrm{NaCl}$ score) - (pre-treatment $\mathrm{NaCl}$ score)] is shown in Figure 1.

For all patients, using a paired Student's t-test, there was no significant difference in pre-treatment identification or threshold scores between right and left nasal cavities $(p=0.37$ and 0.57 respectively), indicating that the use of contralateral nasal cavity for our placebo control was appropriate.

To determine whether application of sodium citrate resulted in increased olfactory scores compared to placebo, changes in 

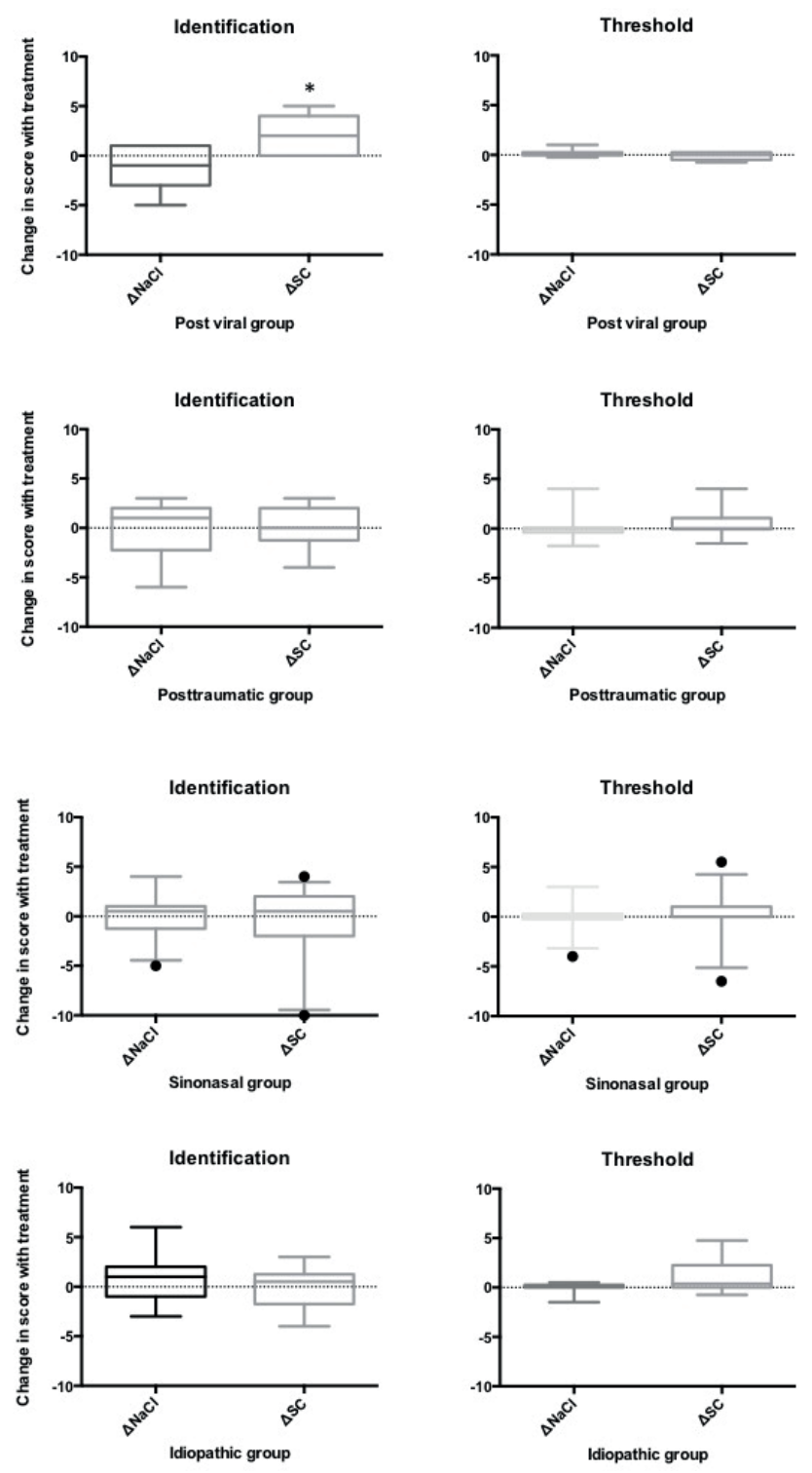

Figure 1. Box and whisker plots showing change in olfactory score with treatment in $\mathrm{SC}(\triangle \mathrm{SC})$ and $\mathrm{NaCl}(\triangle \mathrm{NaCl})$, according to aetiology. Whiskers $=95 \%$ confidence interval. Dots $=$ outliers. ${ }^{*}=$ statistically significant difference between treatment and placebo.

score after treatment were compared using paired Student's t-tests ( $\triangle \mathrm{SC}$ vs. $\triangle \mathrm{NaCl}$ ). Results are shown in Table 3 and Figure 1. The largest difference after treatment (mean improvement of $2.29 \pm 1.89$ ) and the only statistically significant improvement with sodium citrate treatment compared with placebo was seen in the identification scores of post-viral hyposmic patients $(p=$ 0.02). As shown in Table 3, there was no significant difference in threshold scores after treatment in this group (mean change $-0.10 \pm 0.38(\mathrm{SC})$ vs. $0.18 \pm 0.40(\mathrm{NaCl}), \mathrm{p}=0.08)$.

Within the post-viral group, monorhinal identification scores improved after sodium citrate administration in 5 out of 7 patients, and were unchanged in the remaining 2 . In 3 of these patients, the identification score increased by $\geq 3$ points (maximum 5 points). After $\mathrm{NaCl}$ administration, monorhinal identification scores improved in 3 patients (by 1 point each) and deteriorated in the remaining 4 . With regards to monorhinal threshold scores in this group, 2 patients' scores improved (by 0.25 points each), 3 remained the same and 2 deteriorated after sodium citrate administration. After $\mathrm{NaCl}$ administration, the monorhinal threshold scores of 3 patients improved, 3 remained unchanged, and 1 deteriorated.

Sodium citrate was generally well tolerated. Nasal discharge (anterior or posterior) was the commonest side effect seen. However, mild burning or foreign body sensation in either the nose or throat were also reported.

\section{Discussion}

In this prospective placebo controlled, single-blind trial of intranasal sodium citrate for the treatment of hyposmia, we found a statistically significant improvement in identification scores following treatment of patients with post-viral hyposmia, compared with control.

It has been theorised that intranasal sodium citrate may improve olfactory function in hyposmic patients by reducing free calcium found within the nasal mucus layer. As outlined above, calcium has an inhibitory role in olfactory signal transduction, which is thought to involve calcium-calmodulin dependent interference with CNGs and calcium dependent phosphorylation and thereby deactivation of adenylyl cyclase ${ }^{(11-17)}$. The reduction of free calcium concentration within the nasal mucus layer may prevent the intracellular calcium influx required for these inhibitory actions. Clinical work investigating this hypothesis, however, is limited.

In 2005, Panagiotopoulos et al. showed that intranasal instillation of sodium citrate solution in 31 hyposmic patients led to statistically significant improvements in Sniffin' Sticks identification scores, compared with pre-treatment scores $(p<0.001)^{(18)}$. In addition to their psychophysical findings, $74.2 \%$ of patients reported subjective short-lived olfactory improvements. Whilst subgroup analysis according to aetiology was not performed, the majority of the patients in this study $(n=18)$ were post-viral hyposmics. One may argue that their results are therefore in keeping with the identification score improvements we demonstrated in our post-viral group. Our study, however, utilised contralateral monorhinal sodium chloride solution as placebo control, which we would suggest lends strength to our results, despite our small sample size $(n=7)$. Furthermore, unlike Panagiotopoulos who utilised repeated identification testing every 15 minutes after treatment, we tested identification before treatment and 
Table 1. Patient demographics according to hyposmia aetiology. * Surgery= one or more of functional endoscopic sinus surgery, septoplasty, submucosal resection of septum, reduction of nasal bone fracture or reduction of inferior turbinates.

\begin{tabular}{|c|c|c|c|c|}
\hline & Post-viral & Posttraumatic & Sinonasal disease & Idiopathic \\
\hline $\mathrm{N}$ & 7 & 10 & 30 & 10 \\
\hline Age $(\mu \pm S D)$ & $56.57 \pm 16.31$ & $50.70 \pm 12.59$ & $50.80 \pm 17.26$ & $59.2 \pm 14.37$ \\
\hline Gender (\% female) & $3 F, 4 M(42.86 \%)$ & $5 \mathrm{~F}, 5 \mathrm{M}(50 \%)$ & $13 \mathrm{~F}, 17 \mathrm{M}(43.33 \%)$ & $6 \mathrm{~F}, 4 \mathrm{M}(60 \%)$ \\
\hline \multicolumn{5}{|c|}{ Duration of hyposmia } \\
\hline$<3 / 12$ & $0(0 \%)$ & $1(10 \%)$ & $0(0 \%)$ & $0(0 \%)$ \\
\hline $3-24 / 12$ & $4(57.14 \%)$ & $6(60 \%)$ & $10(33.33 \%)$ & $4(40 \%)$ \\
\hline$>24 / 12$ & $3(42.86 \%)$ & $3(30 \%)$ & $20(66.67 \%)$ & $6(60 \%)$ \\
\hline Past medical history & $\begin{array}{l}\cdot \text { Hypertension } \\
\text { •Hyper-cholesterolaemia } \\
\text { - Chronic kidney disease } \\
\text {-Atrial fibrillation } \\
\text {-Atrial regurgitation } \\
\text {-Hypothyroidism }\end{array}$ & $\begin{array}{l}\text { •Hypertension } \\
\text {-Hyper-cholesterolae- } \\
\text { mia } \\
\text { - Gout } \\
\text { - Diabetes } \\
\text { - Osteoporosis } \\
\text { - Hypothyroidism } \\
\text {-Epilepsy }\end{array}$ & $\begin{array}{l}\text {-Hypertension } \\
\text { - Ischaemic heart disease } \\
\text { - Diabetes } \\
\text {-Asthma } \\
\text { - Lymphoma } \\
\text { - Osteoporosis } \\
\text {-Hypothyroidism }\end{array}$ & $\begin{array}{l}\cdot \text { Hypertension } \\
\text {-Hyper-cholesterolaemia } \\
\text { - Gout } \\
\text { - Diabetes } \\
\text { - Vitamin D deficiency } \\
\text {-Hypothyroidism } \\
\text { - Lyme disease }\end{array}$ \\
\hline Current medication & $\begin{array}{l}\text { - B blocker } \\
\text {-ACE inhibitor } \\
\text {-Statin } \\
\text { - L-thyroxine } \\
\text {-HRT }\end{array}$ & $\begin{array}{l}\text {-ACE inhibitor } \\
\text {-Statin } \\
\text { - L-thyroxine } \\
\text { - Metformin } \\
\text {-Allopurinol } \\
\text { - Levetiracetam } \\
\text {-OCP }\end{array}$ & $\begin{array}{l}\text {-ACE inhibitor } \\
\text {-Statin } \\
\text {-Aspirin } \\
\text { - L-thyroxine } \\
\text { - Metformin } \\
\text {-Insulin } \\
\text {-Amlodipine } \\
\text {-PPI } \\
\text {-OCP }\end{array}$ & $\begin{array}{l}\text { - B blocker } \\
\text {-ACE inhibitor } \\
\text { - Statin } \\
\text {-Allopurinol } \\
\text { - L-thyroxine } \\
\text {-Preterax }\end{array}$ \\
\hline $\begin{array}{l}\text { Previous hyposmia } \\
\text { treatment }\end{array}$ & $\begin{array}{l}\cdot \text { None }(n=3) \\
\cdot \text { Topical steroids }(n=2) \\
\text { - Systemic + topical steroids } \\
(n=1) \\
\text { - Systemic steroids + vita- } \\
\text { min A }(n=1)\end{array}$ & $\begin{array}{l}\text {-None }(n=7) \\
\text {-Vitamin A - no response } \\
(n=3)\end{array}$ & $\begin{array}{l}\text { - None }(n=13) \\
\text { - Topical steroids }(n=6) \\
\text { - Systemic }+ \text { topical steroids }(n=2) \\
\text { - Surgery* only }(n=3) \\
\text { - Surgery* }+ \text { topical steroids }(n=1) \\
\text { - Surgery* + systemic steroids }(n=1) \\
\text { - Surgery* + topical + systemic } \\
\text { steroids }(n=3) \\
\text { - Oral antibiotics }(n=1)\end{array}$ & $\begin{array}{l}\cdot \text { None }(n=6) \\
\text { - Systemic steroids }(n=1) \\
\text { - Systemic + topical steroids } \\
(n=1) \\
\cdot \text { Surgery* only }(n=1) \\
\text { - Surgery* + systemic }+ \\
\text { topical steroids }(n=1)\end{array}$ \\
\hline
\end{tabular}

then once only after treatment, in an effort to avoid any potential confounding due to learning.

In 2015, Lam et al. investigated the effect of nasal irrigation with solutions of varying ionic concentrations, on olfactory Sniffin' Sticks threshold levels, in healthy volunteers ${ }^{(21)}$. In doing so, they tested 3 solutions with calcium concentrations of $0.44 \mathrm{mM}$, $0.54 \mathrm{mM}$ (physiological) and $0.64 \mathrm{mM}$. They found that olfactory thresholds increased (i.e. worsened) with concentrations above and below physiological levels, the latter of which was statistically significant. Whilst we did not see any significant improvements in threshold scores, comparison of this study with our work is difficult, given that Lam et al. used healthy volunteers as opposed to hyposmic patients. Furthermore, it is not clear whether irrigation with low calcium solutions produces mucus calcium concentrations similar to those produced by calcium sequestration with sodium citrate solution.

It is therefore not clear why our identification scores improved in post-viral patients, but not threshold scores. It is also unclear why olfactory identification scores improved in the post-viral but no other aetiological subgroups.

When addressing these questions, one must bear in mind that the neurobiochemical role of calcium in olfactory signal transduction is complex and not limited to inhibitory feedback. It is known that following CNG activation, calcium forms a large part of the positive cation influx required for action potential generation ${ }^{(22)}$. This intracellular calcium then goes on to activate calcium-dependent chloride channels in the ON ciliary membrane. Resultant chloride efflux leads to amplification of the transduction signal ${ }^{(23)}$. So, by contributing to the positive 
Table 2. Olfactory scores for threshold and identification in pre and post treatment nasal cavities.

\begin{tabular}{|c|c|c|c|c|c|}
\hline & All patients & Post-viral & Posttraumatic & Sinonasal disease & Idiopathic \\
\hline $\mathrm{N}$ & 57 & 7 & 10 & 30 & 10 \\
\hline \multicolumn{6}{|c|}{ Threshold scores (mean \pm SD) } \\
\hline Pre-treatment $\mathrm{NaCl}$ & $1.94 \pm 1.64$ & $1.21 \pm 0.27$ & $1.60 \pm 1.31$ & $2.17 \pm 1.63$ & $2.10 \pm 2.46$ \\
\hline Post-treatment $\mathrm{NaCl}$ & $2.04 \pm 1.58$ & $1.39 \pm 0.43$ & $1.75 \pm 1.76$ & $2.27 \pm 1.53$ & $2.10 \pm 2.04$ \\
\hline Pre-treatment SC & $2.05 \pm 1.59$ & $2.39 \pm 2.13$ & $1.53 \pm 0.94$ & $2.12 \pm 1.67$ & $2.13 \pm 1.56$ \\
\hline Post-treatment SC & $2.39 \pm 2.03$ & $2.29 \pm 2.05$ & $2.05 \pm 1.59$ & $2.24 \pm 1.85$ & $3.25 \pm 2.89$ \\
\hline \multicolumn{6}{|c|}{ Identification scores (mean \pm SD) } \\
\hline Pre-treatment $\mathrm{NaCl}$ & $7.14 \pm 3.63$ & $5.29 \pm 3.40$ & $5.70 \pm 2.95$ & $8.43 \pm 3.42$ & $6.00 \pm 4.00$ \\
\hline Post-treatment $\mathrm{NaCl}$ & $7.10 \pm 3.87$ & $4.00 \pm 1.53$ & $5.6 \pm 3.24$ & $8.43 \pm 3.90$ & $6.80 \pm 3.99$ \\
\hline Pre-treatment SC & $7.46 \pm 3.85$ & $5.57 \pm 3.65$ & $6.00 \pm 1.76$ & $8.53 \pm 3.87$ & $7.00 \pm 4.81$ \\
\hline Post-treatment SC & $7.44 \pm 4.12$ & $7.86 \pm 3.71$ & $6.00 \pm 2.71$ & $8.00 \pm 4.30$ & $6.90 \pm 5.10$ \\
\hline
\end{tabular}

Table 3. Results from paired t-tests comparing $\Delta \mathrm{NaCl}$ [where $\Delta \mathrm{NaCl}=$ (post treatment $\mathrm{NaCl}$ score) - (pre-treatment $\mathrm{NaCl}$ score)] with $\Delta \mathrm{SC}[[$ where $\Delta \mathrm{SC}$ $=$ (post treatment SC score) - (pre-treatment SC score)] by aetiology for threshold and identification. Statistical significance is indicated by ${ }^{*}$.

\begin{tabular}{|c|c|c|c|c|c|}
\hline & All patients & Post-viral & Posttraumatic & Sinonasal disease & Idiopathic \\
\hline \multicolumn{6}{|c|}{ Threshold } \\
\hline $\mathrm{t}$ & 0.92 & 2.07 & 0.43 & 0.07 & 1.85 \\
\hline df & 56 & 6 & 9 & 29 & 9 \\
\hline $\mathrm{p}$ value & 0.36 & 0.08 & 0.68 & 0.94 & 0.10 \\
\hline \multicolumn{6}{|c|}{ Identification } \\
\hline $\mathrm{t}$ & 0.04 & 3.10 & 0.08 & 0.90 & 1.01 \\
\hline df & 56 & 6 & 9 & 29 & 9 \\
\hline$p$ value & 0.97 & $0.02^{*}$ & 0.94 & 0.38 & 0.34 \\
\hline
\end{tabular}

inward current through CNGs and by activating the calciumdependent chloride channel, calcium has an excitatory role in odorant signal transduction. With the current literature base, it is difficult to postulate how intranasal calcium sequestration leads to improved olfactory function in post-viral hyposmics. More research is needed, at both a clinical level and in animal models of hyposmia.

\section{Conclusion}

We have demonstrated that a single intranasal application of sodium citrate solution improves olfactory identification scores in patients with post-viral hyposmia, compared with placebo. We suggest that further research in this patient group should be undertaken.

\section{Authorship contribution}

KLW: data analysis and write up; CM: draft of study, conduct of all measurements, help with data analysis, help with write up MC: administrative support, help with write up; $\mathrm{AH}$ : administrative support, help with write up; CP: draft of study, help with write up; TH: draft of study, administrative support, data analysis, help with write up.

\section{Conflict of interest}

None.

\section{References}

1. Bhattacharyya N, Kepnes LJ. Contemporary assessment of the prevalence of smell and taste problems in adults. Laryngoscope

2015; 125(5): 1102-1106.

2. Kern DW, Wroblewski KE, Schumm LP, Pinto
JM, Chen RC, McClintock MK. Olfactory Function in Wave 2 of the National Social Life, Health, and Aging Project. J Gerontol B 
Psychol Sci Soc Sci 2014; 69(2), S134-S143.

3. Mullol J, Alobid I, Mariño-Sánchez F, et al. Furthering the understanding of olfaction, prevalence of loss of smell and risk factors: a population-based survey (OLFACAT study). BMJ Open 2012; 2: e001256.

4. Vennemann MM, Hummel T, Berger K. The association between smoking and smell and taste impairment in the general population. J Neurol 2008; 255(8): 1121-1126.

5. Murphy C, Schubert CR, Cruickshanks KJ, Klein BE, Klein R, Nondahl DM. Prevalence of olfactory impairment in older adults. JAMA 2002; 288(18): 2307-12.

6. Croy I, Nordin S, Hummel T. Olfactory disorders and quality of life-an updated review. Chem Senses 2014; 39(3): 185-94.

7. Philpott C, Boak D. The impact of olfactory disorders in the United Kingdom. Chem Senses 2014; 39(8): 711-718.

8. Buck L. Smell and Taste: The Chemical Senses. In: Kandel E, Schwartz J, Jessell T, eds. Principles of Neural Science. New York, NY: McGraw-Hill Medical; 2000: 625-630.

9. Kurahashi T, Shibuya T. Ca2(+)-dependent adaptive properties in the solitary olfactory receptor cell of the newt. Brain Res 1990, 515: 261-268.

10. Zufall F, Shepherd GM, Firestein S. Inhibition of the olfactory cyclic-nucleotide gated ion channel by intracellular calcium. Proc $R$ Soc Lond B Biol Sci 1991, 246: 225-230.

11. Kramer RH, Siegelbaum SA. Intracellular $\mathrm{Ca} 2+$ regulates the sensitivity of cyclic nucleotide-gated channels in olfactory receptor neurons. Neuron 1992, 9: 897-906.

12. Chen TY, Yau KW. Direct modulation by
Ca2+-calmodulin of cyclic nucleotide-activated channel of rat olfactory receptor neurons. Nature 1994, 368: 545-548.

13. Liu M, Chen TY, Ahamed B, Li J, Yau KW. Calcium-calmodulin modulation of the olfactory cyclic nucleotide-gated cation channel. Science 1994, 266: 1348-1354.

14. Wayman GA, Impey S, Storm DR. Ca2+ inhibition of type III adenylyl cyclase in vivo. Biol Chem 1995, 270: 21480-21486.

15. Wei J, Wayman G, Storm DR. Phosphorylation and inhibition of type II adenylyl cyclase by calmodulin-dependent protein kinase II in vivo. J Biol Chem 1996, 271:24231-24235

16. Wei J, Zhao AZ, Chan GCK et al. Phosphorylation and inhibition of olfactory adenylyl cyclase by CaM kinase II in neurons: a mechanism for attenuation of olfactory signals. Neuron 1998, 21: 495-504.

17. Pifferi S, Menini A, Kurahashi T. Signal Transduction in Vertebrate Olfactory Cilia. In: Menini A, ed. The Neurobiology of Olfaction. Boca Raton, Fl: CRC Press/Taylor \& Francis; 2010: 203-224.

18. Panagiotopoulos G, Naxakis S Papavasiliou A, Filipakis K, Papatheodorou G, Goumas P. Decreasing nasal mucus Ca++ improves hyposmia. Rhinology 2005: 43(2): 130-4.

19. Kobal G, Klimek $L$, Wolfensberger $M$ et al. Multicenter investigation of 1,036 subjects using a standardized method for the assessment of olfactory function combining tests of odor identification, odor discrimination, and olfactory thresholds. Eur Arch Otorhinolaryngol. 2000; 257(4): 205-11.
20. Hummel T, Sekinger B, Wolf SR, Pauli E, Kobal G. 'Sniffin' Sticks': Olfactory performance assessed by the combined testing of odor identification, odor discrimination and olfactory thershold. Chem Senses 1997; 22:39-52.

21. Lam K, Conley DB, Liu K, Kern RC, Tan BK Richter CP. Effect of ionic compositions in nasal irrigations on human olfactory thresholds. Laryngoscope. 2015; 125(2): E50-6.

22. Frings $S$, Seifert R, Godde M, Kaupp UB Profoundly different calcium permeation and blockage determine the specific function of distinct cyclic nucleotide-gated channels. Neuron 1995, 15: 169-179.

23. Sato K, Suzuki N. The contribution of a Ca2+-activated $\mathrm{Cl}$ - conductance to aminoacid-induced inward current responses of ciliated olfactory neurons of the rainbow trout. J Exp Biol 2000, 203: 253-262.

\section{KL Whitcroft}

TU Dresden

Fetscherstrasse 74

01307 Dresden

Germany

Tel: +49-351-458 4189

Fax +49-351-458 4326

E-mail:k.whitcroft@gmail.com 